\title{
TRACHEOBRONCHIAL SLEEVE RESECTION WITH THE USE OF A CONTINUOUS ANASTOMOSIS: RESULTS OF ONE HUNDRED CONSECUTIVE CASES
}

Cemal Asim Kutlu, MD

Peter Goldstraw, MD, FRCS
Objective: We have used a continuous suture technique for all tracheal and bronchial anastomoses with satisfactory results in our institution. The objective of this article is to review our experience with sleeve resections using this technique and report the associated morbidity and mortality in 100 consecutive cases. Methods: Our experience with sleeve resection using a continuous suture (3-0 polypropylene) technique was reviewed in 100 consecutive cases. The median age of the patients was 53.3 years with a range of 21 to 81 years. There were 54 male patients and 46 female patients. Resection was undertaken for malignant disease in 81 patients, acquired stricture in 14 patients, benign tumor in 4 patients, and trauma in 1 patient. Among 28 patients in whom lung parenchyma was not resected, 16 patients had tracheal resection and 12 had bronchial sleeve resection. Sleeve pneumonectomy was undertaken in 2, sleeve lobectomy in 66, and sleeve segmentectomy in 4. Results: There were 12 postoperative complications (12\%) and 2 postoperative deaths resulting from bronchoatrial fistula and pneumonia (2\%). Stricture as a late complication occurred in 5 patients, 2 of whom required a bronchial stent. Other late complications were bougienage, reanastomosis, and completion pneumonectomy (1 each). Conclusion: Our experience suggests that the results of continuous suture technique are comparable with those from reported series using interrupted suture technique for tracheal and bronchial anastomosis. (J Thorac Cardiovasc Surg 1999;117:1112-7)
$P^{\prime}$ ice-Thomas ${ }^{1}$ performed the first bronchial sleeve resection in 1947 in a patient with a carcinoid tumor of the right main bronchus. Since then sleeve resection, with or without resection of lung parenchyma, has been increasingly applied in the management of a wide range of malignant and benign conditions of the airway and in tumors originating in the lung and extending to the descending bronchus. In the management of lung cancer, sleeve resection was initially used for patients whose pulmonary function was insufficient to permit pneumonectomy, but it is now considered a valid option whenever the anatomy is suitable. ${ }^{2}$ Better understanding of bronchial healing and the vascular supply of the

From the Department of Thoracic Surgery, Royal Brompton Hospital, London, United Kingdom.

Received for publication Dec 7, 1998; revisions requested Jan 8, 1999; revisions received Feb 12, 1999; accepted for publication Feb 19, 1999

Address for reprints: Cemal Asim Kutlu, MD, Nispetiye Cad, Saydam Sok, 20/1, Levent 80600, Istanbul, Turkey.

Copyright (C) 1999 by Mosby, Inc.

$0022-5223 / 99 \$ 8.00+0 \quad \mathbf{1 2 / 1 / 9 8 2 2 2}$ tracheobronchial tree has reduced the mortality and morbidity of sleeve resection. ${ }^{3}$

The major postoperative complications of sleeve resection, dehiscence and stricture, are related to anastomotic problems. These may result from disruption of the vascular supply, and care must be taken to preserve the blood supply of the bronchus at the anastomosis. ${ }^{4}$ Other authors have emphasized the importance of other factors such as the avoidance of tension or infection, which may affect healing. ${ }^{5}$ The anastomotic technique is clearly of importance. Although a variety of suture materials have been used, reports in the past 50 years all have favored an interrupted suture technique.

In our institution, for the last 19 years we have used a continuous suture technique with monofilament, nonabsorbable suture material for all tracheal and bronchial anastomoses with satisfactory results. We have previously described the good results with this technique for the closure of the pneumonectomy stump. ${ }^{6}$ In this report we retrospectively reviewed our experience with sleeve resection using this technique, and we report the associated morbidity and mortality of the technique. 


\section{Patients and method}

In this study, we included 100 consecutive patients undergoing a circumferential resection of the bronchus or the trachea, with or without pulmonary resection, for benign or malignant lesions involving the tracheobronchial tree. Patients undergoing angioplastic procedures and other bronchoplastic procedures such as wedge bronchoplasty were excluded. The patients notes were reviewed retrospectively and follow-up data were obtained from the most recent clinical visit. For patients who died, information was obtained from hospital records and autopsy findings.

In operations for lung cancer, systemic nodal dissection was undertaken routinely, ${ }^{7}$ and nodes were identified by means of the Naruke nodal map. ${ }^{8}$ Postoperatively, the TNM classification system, recently revised, was used for staging. ${ }^{9}$ All complications occurring within 30 days of the operation were classified as early complications. Operative mortality was defined as death occurring within 30 days of the operation or death directly related to the procedure even if it occurred more than 30 days after the operation. Tumor growth at the anastomosis was considered to be a local recurrence regardless of the interval after operation.

Preoperative evaluation. All patients had a chest radiograph and computed tomography (CT) of the chest. In those patients with malignant disease, $\mathrm{CT}$ of the brain and abdomen was performed routinely and magnetic resonance imaging, positron emission tomography, and bone scintigraphy were performed selectively. Arterial blood gas assessment and spirometry were routine, and in the patients with limited lung function a ventilation/perfusion scan was performed. Examination with a fiberoptic bronchoscope was undertaken before the operation for histologic evaluation. Invasive mediastinal staging, using cervical mediastinoscopy and/or anterior mediastinotomy, was undertaken in any patient with malignant disease if the CT of the chest suggested mediastinal involvement. Surgery was not considered in those patients who were proven to have mediastinal nodal involvement. None of the patients in this series received induction therapy with chemotherapy or chemotherapy/radiation therapy.

Operative procedure. It is our routine to use a rigid bronchoscope before thoracotomy to check for intrabronchial lesions and to identify patients in whom bronchoplastic procedures may prove feasible. In operations for lesions beyond the main carina, the patients were intubated with a doublelumen endobronchial tube. In operations for lesions of the trachea or carina, an endotracheal tube was preferred. When necessary, ventilation of the opposite lung was continued with the aid of a Venturi technique or an additional endobronchial tube inserted across the operative field. A standard posterolateral thoracotomy was undertaken for lesions of one lung, the distal trachea, and/or carina. A collar incision was used for lesions of the upper trachea.

In operations for lung cancer, our technique did not differ until the bronchus was isolated. We tried not to devascularize the bronchus beyond the line of section, although our systematic nodal dissection usually led to the division of all bronchial vessels. The bronchus was divided after placement of stay sutures to orientate the proximal and distal lumina. Frozen section analysis of the proximal and distal margins was routinely performed to confirm that they were free of disease. The distal transection line was made as close as possible to the lobar origin to maximize any retrograde flow from the bronchial vessels. The anastomosis was performed with a double-ended suture of 3-0 polypropylene (Prolene, Ethicon Inc, Somerville, NJ), commencing at the far side of the membranous wall of the airway and continuing in a continuous suture around the cartilaginous wall, leaving the membranous wall until last to allow for any disparity between the crosssectional area of the distal and proximal orifices. When the trachea was sutured, additional sutures of 2-0 polypropylene were placed through the entire thickness of the airway at each quadrant and tied at the completion of the anastomosis. Cartilage-to-cartilage apposition was achieved with an open suture technique, the ends being pulled together at the completion of the anastomosis without distortion. After completion of the anastomosis, the suture line was checked for air leaks by inflating the lung after immersing the anastomosis under fluid. The anastomosis was not covered with any soft tissue wrap. The inferior pulmonary ligament was divided in those patients undergoing lateral thoracotomy to decrease the tension at the anastomosis. Postoperative bronchoscopy was not performed routinely. Careful bronchial suctioning was performed through the endobronchial/endotracheal tube at the end of the procedure. Patients were extubated in the operating theater immediately after the procedure. Chin sutures were used to maintain flexion in patients who had tracheal or carinal resection. Steroids were not used in any of these patients.

\section{Results}

Fifty-four $(54 \%)$ of these patients were male. The ages of the patients ranged from 21 to 81 years (average 53.3 years). The indication for operation was a malignant tumor in 81 patients, an acquired stricture in 14 , a benign tumor in 4 , and a traumatic lesion in 1 patient. Indications for sleeve resection and the extent and localization of the resections are given in Table I.

Tracheal sleeve resection was undertaken in 16 patients. Nine of these patients had benign stricture resulting from previous intubation or tracheostomy. Seven patients had a tracheal tumor, 4 had squamous cell carcinoma, and 1 each had neuroendocrine carcinoma, granular cell tumor, and chemodectoma. Resections were undertaken through a right thoracotomy in 6 patients and through a cervical incision in 10 patients in whom the lesion was localized in the upper trachea. Airway continuity was established with endto-end anastomosis in all of these patients.

Bronchial sleeve resection without removal of lung parenchyma was performed in 12 patients (carcinoid tumor in 4 , benign stricture in 4 , malignant tumor in 2 
Table I. Indications and types of sleeve resections

\begin{tabular}{|c|c|c|c|c|c|c|}
\hline & \multirow[b]{2}{*}{ Tracheal SR } & \multirow[b]{2}{*}{ Bronchial SR } & \multicolumn{3}{|c|}{$S R+L R$} & \multirow[b]{2}{*}{ No. of patients } \\
\hline & & & Pneumonectomy & Lobectomy & Segmentectomy & \\
\hline Malignant tumor & 5 & 6 & 2 & 64 & 4 & 81 \\
\hline Acquired stricture & 9 & 4 & - & 1 & - & 14 \\
\hline Benign tumor & 2 & 1 & - & 1 & - & 4 \\
\hline Trauma & - & 1 & - & - & - & 1 \\
\hline Total & 16 & 12 & 2 & 66 & 4 & 100 \\
\hline
\end{tabular}

$S R$, Sleeve resection; $L R$, lung resection.

Table II. Mortality and morbidity of sleeve resection in this series

\begin{tabular}{lll}
\hline & No. \\
\hline Mortality (2\%) & & \\
$\quad$ Bronchoatrial fistula & 1 & \\
Pneumonia & 1 & 2 \\
Total & & \\
Morbidity (12\%) & 3 & \\
Pneumothorax & 2 & \\
Atrial fibrillation & 2 & \\
Anastomotic dehiscence & 1 & \\
Pneumonia & 1 & \\
Gastrointestinal bleeding & 1 & \\
Persistent air leak & 1 & \\
Pseudomembranous colitis & 1 & \\
Deep venous thrombosis & & 12 \\
Total &
\end{tabular}

[squamous cell carcinoma and mucoepidermoid carcinoma], benign tumor in 1, and traumatic rupture in 1). All of these resections were performed through a lateral thoracotomy. On the left side, adequate exposure was obtained below the aortic arch by mobilization of the pulmonary artery and division of the ligamentum arteriosum.

A right sleeve pneumonectomy was undertaken in 2 patients with malignant lung tumors (adenoid cystic carcinoma and squamous cell carcinoma), which were found at operation to be involving the carina. Standard thoracotomy was used for both patients. No patient had a carinal resection with a 3-part anastomosis in this series.

Sleeve lobectomy was performed in 66 patients: for lung cancer in 41 patients, carcinoid tumor in 22 (including 18 typical and 4 atypical tumors), metastatic sarcoma in 1, post-tuberculosis stricture in 1, and fibrous histiocytoma in 1 patient. Two of these patients, who underwent a right upper lobectomy and sleeve resection for lung cancer, had concomitant chest wall resection.
Four patients had sleeve segmentectomy (lingulectomy in 2 and resection of the apical segment of the lower lobe in 2). Three of them had carcinoid tumor and the fourth had stage I squamous cell carcinoma. All these patients were considered able to tolerate major lung resection if necessary. Limited resection with curative intent was considered justified once shown at thoracotomy to be technically feasible and appropriate.

Forty-four patients underwent sleeve resection for lung cancer. The cancer stages were as follows: stage IA in 7 (T1 N0) and IB in 17 (T2 N0); stage IIB in 11 (T2 N1 in 3, T3 N0 in 8); stage IIIA in 7 (T3 N1 in 3, T1-3 N2 in 4) and stage IIIB in 2 (T4 N0). Six patients had N1 disease, with single station involvement of lymph node No. 10 in 2 patients, No. 11 in 3 patients, and No. 12 in 1 patient. In 4 patients systematic nodal dissection revealed N2 disease: station No. 5 and/or No. 6 in 2 patients and station No. 7 in the other 2 patients.

Follow-up was from 6 months to 14 years (median 4.3 years). At the time of follow-up, the clinical condition of patients who had undergone sleeve resection for benign disease improved or remained the same. Three patients died in this group because of causes unrelated to the original disease. In the group of patients undergoing sleeve resection for lung cancer, 2 had locoregional recurrence (2/44). Fourteen patients died of relapse $(32 \%)$.

Inasmuch as the purpose of this paper is to present the results of the surgical technique, we did not undertake more detailed analysis of the survival data.

Postoperative complications. Postoperative complications are listed in Table II. The morbidity of sleeve resection was $12 \%$ in this study. Three patients had a postoperative pneumothorax but we did not undertake bronchoscopy; the pneumothorax resolved without treatment in 2 patients and necessitated chest tube insertion in 1. Partial anastomotic dehiscence was confirmed by bronchoscopy in 3 patients, occurring between 4 and 12 days after operation. In 1 patient 
completion pneumonectomy was performed on the fifteenth postoperative day to control infection and an air leak. In a second patient the anastomosis healed and the air leak spontaneously stopped without further treatment. In the third patient partial bronchial dehiscence was associated with a bronchoatrial fistula, causing death on the ninth postoperative day as a result of massive hemorrhage. The other postoperative death was caused by pneumonia and cerebral infarction after tracheal sleeve resection, for an overall operative mortality of $2 \%$ (Table II).

Stenosis developed in 5 patients as a late complication (5\%), being diagnosed between 4 and 9 months after the operation (Table III). Of these patients, 3 had sleeve lobectomy and the others had a tracheal and bronchial sleeve resection. One patient who had had a partial dehiscence that healed without further treatment returned with a stenosis 8 months after the operation. She underwent resection of the stenotic tracheal segment and reanastomosis. The patient died 4 years after the second operation of chronic obstructive pulmonary disease. In 2 patients the stenosis was treated with a stent. They remain well with functioning lung distal to the stent at follow-up 8 and 9 years later. In 1 patient the stenosis resolved with bougienage and the patient remains well on follow-up at 2 years. Completion pneumonectomy was undertaken in the fifth patient because of irreversible parenchymal damage distal to the stenosis.

\section{Discussion}

Sleeve resection, with or without lung resection, is a valid conservative operation for patients with benign or malignant tumors, allowing conservation of lung parenchyma. In reported series the mortality of sleeve resection ranged from $1.3 \%$ to $7.7 \%$ and the morbidity from $2.5 \%$ to $11 \%$; these figures are comparable with the risks associated with standard resections. The frequency of airway complications has been reduced significantly over the years, ${ }^{10-12}$ and this has been attributed to better bronchial healing with preservation of the bronchial blood supply, performing the anastomosis without any tension, improved suture materials, and placing knots outside the lumen. ${ }^{13}$ The mortality and morbidity in our series is comparable with the reported results obtained with an interrupted suture technique (Table III), suggesting that anastomotic technique overall does not affect outcomes after sleeve resection.

Van Schil and associates ${ }^{14}$ reported that the rate of stenosis was $14.3 \%$ when a continuous anastomosis was undertaken with polypropylene or Teflon-coated polyester sutures and only $5.7 \%$ after interrupted suture
Table III. Mortality and morbidity of sleeve resection with interrupted and continuous suture technique

\begin{tabular}{lccc}
\hline & & \multicolumn{2}{c}{ Results in this series } \\
\cline { 3 - 4 } & $\begin{array}{l}\text { Results in the } \\
\text { literature (\%) }\end{array}$ & $\begin{array}{c}\text { No. of } \\
\text { patients }\end{array}$ & $\%$ \\
\hline Thirty-day mortality & $1.3-7.7$ & $2 / 100$ & 2 \\
Local recurrence & $7-20$ & $2 / 44$ & $4.1 *$ \\
Pneumonia & $1.4-21.1$ & $2 / 100$ & 2 \\
Stenosis & $2.8-8.7$ & $5 / 100$ & 5 \\
Bronchopleural fistula & $0.6-3.5$ & $2 / 100$ & 2 \\
Bronchovascular fistula & $2-2.6$ & $1 / 100$ & 1 \\
\hline
\end{tabular}

*Includes the patients who had sleeve resection for non-small cell lung cancer.

with polyglactin. The rate of stenosis in our series (5\%) is comparable with that of the latter group in their report. Hsieh and colleagues ${ }^{15}$ performed bronchial anastomosis in puppies using interrupted or continuous suture techniques with absorbable (Dexon-S [Davis \& Geck, Danbury, Conn], Vicryl [Ethicon]) and nonabsorbable (Prolene [Ethicon], nylon) suture material. They observed excellent results in the absorbable group regardless of the suture technique used. Relative bronchial stenosis occurred in the growing puppies in which a continuous anastomosis was constructed with nonabsorbable suture material. This study showed that the suture technique, either continuous or interrupted, is feasible for the bronchial anastomosis and that absorbable material is preferable in the pediatric cases.

Healing at the site of tracheal and bronchial anastomoses depends on an adequate blood supply. Even if the bronchial arteries are preserved, cutting and suturing of the bronchus disturbs the bronchial circulation. The anastomosis remains ischemic until the systemic arterial circulation is reestablished in 2 to 4 weeks. ${ }^{16}$ Poor healing results in anastomotic dehiscence and stenosis after the operation. ${ }^{5}$ Retrograde flow has been detected from the pulmonary artery into the bronchial arteries distal to the anastomosis immediately after resection. ${ }^{4}$ However, healing will be impaired if this is the only arterial supply to the anastomosis. Surrounding tissues provide some systemic supply to the distal part of the anastomosis. In an experimental study, Inui and coworkers ${ }^{5}$ measured the mucosal blood flow after sleeve resection with limited or extensive mobilization of the airways. The decrease in the blood flow was significantly greater on the first postoperative day after extensive mobilization $(81 \% \pm 6 \%$ vs $57 \% \pm$ $23 \%$ ), suggesting that retrograde flow from the pulmonary circulation requires additional systemic supplies from adjacent tissues if healing is to occur. 
Systematic nodal dissection is an important part of the intrathoracic reevaluation of the patients with lung cancer but inevitably leads to division of the bronchial arterial supply. We believe, however, that this additional risk is offset by the valuable contribution that systematic nodal dissection makes to the assessment of operability and the extent of resection required for complete resection, and this should therefore be accepted. Debate continues as to whether sleeve resection should be performed in the presence of N1 disease. Undoubtedly much of the earlier confusion was caused by inaccurate nodal dissection, such that many patients with N1 disease had unrecognized N2 disease. One report has found that regional lymph node involvement (N1 disease) did not have an adverse effect on survival after sleeve resection, ${ }^{12}$ with a 5-year survival of $46 \%$. $^{2,12}$

We believe that sleeve resection is a valid option for selected patients with $\mathrm{N} 1$ disease, irrespective of respiratory reserve. In our series, sleeve resection was undertaken with curative intent in 6 patients with N1 disease. Surgery can be curative for limited N2 disease, and sleeve resection should be considered for such patients, especially those with "skip" metastases to N2 nodes. ${ }^{17}$ Many authors have attempted to reduce the problems of bronchial healing after sleeve resection by using a variety of techniques. Lima and colleagues ${ }^{18}$ wrapped the bronchial anastomosis with greater omentum after autotransplantation in the dog and demonstrated systemic blood flow by postoperative day 4 . Such a wrap may be beneficial but certainly extends the operation time. We believe that careful handling of the airways avoids the need for any soft tissue wrap after sleeve resection. Furthermore, the wrap may have an adverse effect on healing if it prevents systemic blood flow from surrounding tissue. This may explain the higher 30-day mortality $(11.1 \%)$ in one study for the group of patients with a pedicled flap when compared with those without any flap $(4.5 \%) .{ }^{19}$ One may consider such a wrap desirable if undertaking resection after induction radiotherapy or in high-risk operations for multidrug-resistant tuberculosis.

Granulation formation at the suture line was the commonest complication in early series reporting the results of sleeve resection..$^{10}$ Modern, synthetic suture materials may have led to a reduced complication rate. Absorbable suture materials (polyglactin 910 [Vicryl], polyglyconate [Maxon, Davis \& Geck]) and nonabsorbable sutures such as polypropylene (Prolene) have been those most commonly used in recent series reporting the results of tracheal and bronchial anastomosis. ${ }^{19-21}$ However, the incidence of stricture formation after sleeve resection in one of our earlier series was $13 \%, 22$ and this has fallen despite our use of the same suture material, suggesting that other factors, such as more careful handling of the bronchus, may be important.

The majority of deaths after resection for lung cancer are due to relapse, mainly at distant sites. ${ }^{10}$ The recurrence rate after sleeve resection $(10.3 \%)$ is higher than that after standard resections, ${ }^{23}$ and yet survivals are comparable with those after pneumonectomy, possibly since patients surviving sleeve resection have the chance for surgical treatment of their recurrent disease, or for the subsequent development of a second primary tumor. Preservation of functional lung tissue by sleeve resection provides a greater exercise capacity and improved quality of life..$^{21,24}$ We believe that sleeve resection should be the resection of choice in any patient in whom the anatomy is suitable, irrespective of their physiologic reserve.

Our experience suggests that the results of sleeve resection using a continuous anastomosis are comparable with those reported with an interrupted technique. Bronchial blood supply is adequate for healing unless the bronchus is excessively mobilized. The continuous suture is quick and technically easier to perform and has been safe in the hands of a large number of trainees in our institution. Postoperative outcomes suggest that it is also safe in the long term.

\section{REFERENCES}

1. Price-Thomas $\mathrm{C}$. Conservative resection of the bronchial tree. J R Coll Surg Edinb 1956;3:168.

2. Gaissert HA, Mathisen DJ, Moncure AC, Hilgenberg AD, Grillo HC, Wain JC. Survival and function after sleeve lobectomy for lung cancer. J Thorac Cardiovasc Surg 1996;111:948-53.

3. Faber LP, Jensik RJ, Kittle FC. Results of sleeve for lobectomy for bronchogenic carcinoma in 101 patients. Ann Thorac Surg 1984;37:279-85.

4. Ishihara T, Nemoto E, Kikuchi K, Kato R, Kobayashi K. Does pleural bronchial wrapping improve wound healing in right sleeve lobectomy? J Thorac Cardiovasc Surg 1985;89:665-72.

5. Inui K, Wada H, Yokomise H, Lee M, Yamazaki F, Aoki M, et al. Evaluation of bronchial anastomosis by laser Doppler velocimetry. J Thorac Cardiovasc Surg 1990;99:614-9.

6. Al-Kattan K, Cattelani L, Goldstraw P. Bronchopleural fistula after pneumonectomy for lung cancer. Eur J Cardiothorac Surg 1995;9:479-82.

7. Goldstraw P. Report on the International Workshop in Intrathoracic Staging. Lung Cancer 1997;18:107-11.

8. Naruke T, Suemasu K, Ishikawa S. Lymph node mapping and curability at various levels of metastases in resected lung cancer. J Thorac Cardiovasc Surg 1978;76:832-9.

9. Mountain CF. Revisions in the International System for Staging Lung Cancer [see comments]. Chest 1997;111:1710-7A.

10. Jensik RJ, Faber LP, Milloy FJ, Amato JJ. Sleeve lobectomy for carcinoma: a ten-year experience. J Thorac Cardiovasc Surg 1972;64:400-12. 
11. Watanabe Y, Shimizu J, Oda M, Hayashi Y, Watanabe S, Yazaki $\mathrm{U}$, et al. Results in 104 patients undergoing bronchoplastic procedures for bronchial lesions. Ann Thorac Surg 1990;50:607-14.

12. Mehran RJ, Deslauriers J, Piraux M, Beaulieu M, Guimont C, Brisson J. Survival related to nodal status after sleeve resection for lung cancer. J Thorac Cardiovasc Surg 1994;107:576-83.

13. Rendina EA, Venuta F, Ricci C. Effects of low-dose steroids on bronchial healing after sleeve resection: a clinical study. J Thorac Cardiovasc Surg 1992;104:888-91.

14. Van Schil PE, de la Rivière AB, Knaepen PJ, Swieten HA, Defauw JJ, van den Bosch JM. Completion pneumonectomy after bronchial sleeve resection: incidence, indications and results. Ann Thorac Surg 1992;53:1042-5.

15. Hsieh CM, Tomita M, Ayabe H, Kawahara K, Hasegawa H, Yoshida R. Influence of suture on bronchial anastomosis in growing puppies. J Thorac Cardiovasc Surg 1988;95:998-1002.

16. Stone RM, Ginsburg RJ, Colapinto RF, Pearson FC. Bronchial artery regeneration after radical hilar stripping. Surg Forum 1966;17:109-10.

17. Graham ANJ, Chan KJM, Pastorino U, Goldstraw P. Systematic nodal dissection in the intrathoracic staging of patients with non-small cell lung cancer. J Thorac Cardiovasc Surg 1999;117: 246-51.
18. Lima O, Goldberg M, Peters WJ, Ayabe H, Townsend E, Cooper JD. Bronchial omentopexy in canine lung transplantation. J Thorac Cardiovasc Surg 1982;83:418-21.

19. Rea F, Loy M, Bortolotti L, Feltracco P, Fiore D, Sartori F. Morbidity, mortality and survival after bronchoplastic procedures for lung cancer. Eur J Cardiothorac Surg 1997;11:2015.

20. Naruke T. Bronchoplastic and bronchovascular procedures of the tracheobronchial tree in the management of primary lung cancer. Chest 1989;96(suppl):53S-6S.

21. Frist WH, Mathisen DJ, Hilgenberg AD, Grillo HC. Bronchial sleeve resection with and without pulmonary resection. J Thorac Cardiovasc Surg 1987;93:350-7.

22. Tsang V, Goldstraw P. Endobronchial stenting for anastomotic stenosis after sleeve resection. Ann Thorac Surg 1989;48:56871.

23. Tedder M, Anstadt MP, Tedder SD, Lowe JE. Current morbidity, mortality, and survival after bronchoplastic procedures for malignancy. Ann Thorac Surg 1992;54:387-91.

24. Vogt-Moykopf I, Fritz TH, Meyer G, Bulzerbruck H, Daskos G. Bronchoplastic and angioplastic operation in bronchial carcinoma: long-term results of a retrospective analysis from 1973 to 1983. Int Surg 1986;71:211-20.

\section{Authoritative}

The Journal of Thoracic and Cardiovascular Surgery is the most frequently cited thoracic/cardiovascular surgery journal in the Science Citation Index. An article in JTCVS is sited on average almost twice as often as those in the closest cardiothoracic journal. 